\title{
Concurrence of primary headaches: Lane and Davies (2006) revisited
}

\author{
Andrew J. Larner
}

Received: 21 January 2009/ Accepted: 2 February 2009/Published online: 24 February 2009

(C) Springer-Verlag 2009

Lane and Davies [1] have proposed the hypothesis that all primary headaches are manifestations of a single fundamental pathophysiological process, the migraine mechanism; and hence, lie within a continuum defined by the parameters of headache intensity, inverse frequency and duration, and trigeminal autonomic features. Their argument was based in part on symptomatic overlap between primary headache types, transformation between types over time, existence of intermediate forms, and concurrence of multiple primary headaches in individual patients.

To further examine the validity of Lane and Davies's hypothesis, concurrence of multiple primary headaches in individual patients has been further examined by reviewing data from two previous prospective surveys reported from general neurology outpatient clinics, looking at patients with primary headache associated with sexual activity (PHSA) [2] and trigeminal autonomic cephalalgias (TACs) [3].

In an ongoing study of PHSA [2], of 35 patients seen, 9 $(=25.7 \%)$ had comorbid headache diagnoses, either tension-type headaches (8) or migraine with aura (1). These findings are concordant with another large PHSA cohort reported from a dedicated headache clinic [4].

In a series of $40 \mathrm{TAC}$ patients [3], one patient with cluster headache also had migraine with aura. Lane and Davies [1] reported a similar case (case 222). Another patient in this series had exploding head syndrome, which although not a headache syndrome does suggest neural activation with a disturbance in sensory control, features of the migraine mechanism [1].

These data may reflect chance concurrence of primary headache syndromes, for although they derive from prospective studies they involved relatively selected patient populations, namely neurology outpatient clinic attenders. Patients with more than one headache type might be more likely to be referred to the clinic. Alternatively, the data could be taken as some support for Lane and Davies's hypothesis of phenotypic continuity in primary headache syndromes.

Conflict of interest None.

\section{References}

1. Lane R, Davies P (2006) Migraine. Taylor and Francis, New York, pp 259-278

2. Larner AJ (2006) Late presentation of primary headache associated with sexual activity: is non-invasive angiography worthwhile? J Headache Pain 7:139-140

3. Larner AJ (2008) Trigeminal autonomic cephalalgias: frequency in a general neurology clinic setting. J Headache Pain 9:325-326

4. Frese A, Eikermann A, Frese K, Schwaag S, Husstedt IW, Evers S (2003) Headache associated with sexual activity. Demography, clinical features, and comorbidity. Neurology 61:796-800

\footnotetext{
A. J. Larner $(\square)$

Walton Centre for Neurology and Neurosurgery, Lower Lane, Fazakerley, Liverpool L9 7LJ, UK

e-mail: a.larner@thewaltoncentre.nhs.uk
} 